\title{
Elevated vasoinhibins may contribute to endothelial cell dysfunction and low birth weight in preeclampsia
}

\author{
Carmen González ${ }^{1, *}$, Adalberto Parra ${ }^{2, *}$, Jorge Ramírez-Peredo², Celina García ${ }^{1}$, José Carlos Rivera ${ }^{1}$, \\ Yazmín Macotela', Jorge Aranda', Maria Lemini ${ }^{1}$, José Arias ${ }^{2}$, Francisco Ibargüengoitia ${ }^{2}$, \\ Gonzalo Martínez de la Escalera ${ }^{1}$ and Carmen Clapp ${ }^{1}$
}

Vasoconstriction and defective placental angiogenesis are key factors in the etiology of preeclampsia. Prolactin levels are elevated in maternal blood throughout pregnancy and the human decidua produces prolactin that is transported to the amniotic fluid. Prolactin is cleaved to yield vasoinhibins, a family of peptides that inhibit angiogenesis and nitric oxidedependent vasodilation. Here, we conducted a case-control study to measure vasoinhibins in serum, urine, and amniotic fluid obtained from women with severe preeclampsia. We show that all three biological fluids contained significantly higher levels of vasoinhibins in preeclamptic women than in normal pregnant women. Amniotic fluid from preeclamptic women, but not from normal women, inhibited vascular endothelial growth factor-induced endothelial cell proliferation and nitric oxide synthase activity in cultured endothelial cells, and these actions were reversed by antibodies able to neutralize the effects of vasoinhibins. Furthermore, amniotic fluid does not appear to contain neutral prolactin-cleaving proteases, suggesting that vasoinhibins in amniotic fluid are derived from prolactin cleaved within the placenta. Also, cathepsin-D in placental trophoblasts cleaved prolactin to vasoinhibins, and its activity was higher in placental trophoblasts from preeclamptic women than from normal women. Importantly, birth weight of infants in preeclampsia inversely correlated with the extent to which the corresponding AF inhibited endothelial cell proliferation and with its concentration of prolactin + vasoinhibins. These data demonstrate that vasoinhibins are increased in the circulation, urine, and amniotic fluid of preeclamptic women and suggest that these peptides contribute to the endothelial cell dysfunction and compromised birth weight that characterize this disease.

Laboratory Investigation (2007) 87, 1009-1017; doi:10.1038/labinvest.3700662; published online 6 August 2007

KEYWORDS: angiogenesis; cathepsin-D; nitric oxide; preeclampsia; 16K prolactin; VEGF

Preeclampsia affects about $5 \%$ of all pregnancies and results in substantial maternal and neonatal morbidity and mortality. ${ }^{1}$ Although the etiology of preeclampsia remains unclear, the syndrome may be initiated by placental factors causing endothelial cell dysfunction at the fetomaternal interface and in the systemic maternal circulation. ${ }^{1,2}$ Poor placental and decidual vascularization results in inadequate placental development and may restrict fetal growth, whereas dysregulation of the maternal vascular endothelium leads to hypertension and proteinuria-the clinical manifestations of preeclampsia. ${ }^{1,2}$

Vascular endothelial growth factor (VEGF) is a major promoter of angiogenesis and vasodilation in the placenta. ${ }^{2}$
The actions of VEGF are partially mediated by the production of endothelium-derived nitric oxide $(\mathrm{NO}),{ }^{3}$ a potent vasorelaxant that regulates systemic blood pressure, vascular permeability, and angiogenesis. ${ }^{4}$ Decreased levels of VEGF and NO are seen not only during preeclampsia, but also before the onset of clinical symptoms. ${ }^{5-8}$ Moreover, interference with placental VEGF and NO compromises normal angiogenesis and leads to a poorly perfused fetoplacental unit, hypertension, proteinuria, and fetal growth restriction, ${ }^{6,9-11}$ suggesting that blockage of VEGF and NO has a causal role in preeclampsia.

Prolactin (PRL), originally identified as a lactotrophic hormone secreted by the pituitary gland, is also synthesized

\footnotetext{
'Departamento de Neurobiología Celular y Molecular, Instituto de Neurobiología, Universidad Nacional Autónoma de México (UNAM), Campus UNAM-Juriquilla, Querétaro, México and ${ }^{2}$ Instituto Nacional de Perinatología Isidro Espinosa de los Reyes, Secretaría de Salud, México DF, México

Correspondence: Dr C Clapp, PhD, Departamento de Neurobiología Celular y Molecular, Instituto de Neurobiología, Universidad Nacional Autónoma de México (UNAM), Campus UNAM-Juriquilla, Boulevard Juriquilla 3001, 76230 Querétaro, Qro, México. E-mail: clapp@servidor.unam.mx

${ }^{*}$ These two authors contributed equally to this work. 
in numerous extrapituitary tissues, including the decidual cells in the uterus, from which it is transported to the amniotic fluid (AF) where it reaches high levels. ${ }^{12,13}$ Proteolysis of PRL by cathepsin-D or by matrix metalloproteases produces vasoinhibins, a family of peptides that act on endothelial cells to inhibit vasodilation and angiogenesis and to promote apoptosis-mediated vascular regression. ${ }^{14}$ Vasoinhibins suppress VEGF-induced NO synthase (NOS) activity in endothelial cells, and exogenous NO reverses inhibition by vasoinhibins of VEGF-induced endothelial cell proliferation and acetylcholine-induced vasodilation. ${ }^{15}$ The increased presence of PRL in maternal blood throughout pregnancy ${ }^{16}$ and its synthesis by decidual cells, coupled to the fact that vasoinhibins impair VEGF-dependent activation of endothelial NOS, angiogenesis, and vasodilation, suggest that vasoinhibins may play a role in preeclampsia. The purpose of this study was to determine whether vasoinhibins are present in the serum, urine, and AF from patients with severe preeclampsia, and if they could reduce the proangiogenic actions of VEGF, inhibit NOS activity, and contribute to reducedbirth weight.

\section{MATERIALS AND METHODS Study Population}

The study encompassed 21 pregnant women without history of diabetes mellitus, thyroid, liver, or chronic renal disease attending the Obstetrics Outpatient Department of the 'Instituto Nacional de Perinatología Isidro Espinosa de los Reyes' in Mexico City. All women provided written, informed consent before collection of samples. The Institutional Review Board approved the collection and use of the samples, and the study was conducted according to the third edition of the Guidelines on the Practice of Ethical Committees in Medical Research issued by the Royal College of Physicians of London. The control group included eight clinically healthy, normotensive women between 18 and 38 years of age, with full-term ( $\geq 36$ weeks of gestation) uneventful pregnancies (all singleton), who were undergoing cesarean section for obstetric reasons. The preeclamptic group included 13 previously normotensive women, 16-40 years old with severe preeclampsia diagnosed between 28 and 39 weeks of gestation (all singleton), who were admitted to our institution between 24 and $72 \mathrm{~h}$ after initiation of symptoms (rapid weight gain, headache, and dizziness). They underwent cesarean section immediately after blood pressure was brought under control by medical treatment (methyldopa, diuretics, and diphenylhydantoin). Severe preeclampsia was defined as persistent blood pressure of $\geq 150 / 110 \mathrm{~mm} \mathrm{Hg}$ and proteinuria of $\geq 3 \mathrm{~g}$ in a 24 -h urine sample or $>3+(300 \mathrm{mg} / \mathrm{dl})$ as determined by dipstick testing. All preeclamptic women became normotensive within 2 weeks after the end of pregnancy. In addition, venous blood and urine samples were collected from a group of six volunteer, age-matched, non-pregnant women.

\section{Determination of PRL, Vasoinhibins, and VEGF}

Venous blood, urine, and AF samples were obtained immediately before the cesarean section and centrifuged at 3000 r.p.m. for $20 \mathrm{~min}$; aliquots of the supernatants were stored frozen at $-70^{\circ} \mathrm{C}$. PRL was quantified using an immunoradiometric assay kit (IRMA) (Diagnostic Products Corporation, Los Angeles, CA, USA), with a detection limit of $1.5 \mathrm{ng} / \mathrm{ml}$ and intra- and inter-assay coefficients of variance of $<4$ and $<7.8 \%$, respectively. Vasoinhibins were immunoprecipitated from $750 \mu \mathrm{l}$ of serum or urine with $3 \mu \mathrm{l}$ of anti-human PRL antiserum obtained and characterized as reported ${ }^{17}$ using the previously published technique. ${ }^{18}$ The immunoprecipitates were subjected to SDS-PAGE on a $12 \%$ acrylamide gel under reducing conditions, transferred to nitrocellulose membranes, and probed with $4.2 \mu \mathrm{g} / \mathrm{ml}$ antihuman PRL monoclonal antibodies (mAb 5602, Diagnostic Biochem Canada Inc., London, Ontario, Canada) that react with the $\mathrm{N}$ terminus of PRL. ${ }^{19}$ To assay for vasoinhibins in $\mathrm{AF}, 35 \mu \mathrm{l}$ of AF was processed in 15\% SDS-PAGE western blots probed with the $\mathrm{mAb}$ 5602. Detection of immunoreactive proteins in serum and urine was performed with the SuperSignal West Femto Maximum Sensitivity Substrate kit (Pierce Biotechnology Inc., Rockford, IL, USA); whereas, in the AF they were revealed with the alkaline phosphatase secondary antibody kit (Bio-Rad Laboratories, Hercules, CA, USA). Optical density values were determined using 1D image analysis software, version 3.5 (Eastman Kodak Company, Rochester, NY, USA). Human PRL was obtained from the National Hormone and Pituitary Program (NHPP, Torrance, CA, USA), and human vasoinhibins were generated using a baculovirus expression system. ${ }^{20}$ The AF levels of VEGF were quantified with an enzyme-linked immunosorbent assay (Biosource International Inc., Camarillo, CA, USA). The assay recognizes both natural and recombinant human VEGF-165 with a sensitivity of $5 \mathrm{pg} / \mathrm{ml}$ and has intra- and interassay coefficients of variance of $<4.7$ and $<8.1 \%$, respectively.

\section{Endothelial Cell Culture and Proliferation Assay}

Bovine umbilical vein endothelial cells (BUVEC) were obtained as described previously. ${ }^{21}$ The cells were cultured in F12K medium with $10 \%$ fetal bovine serum and $50 \mathrm{U} / \mathrm{ml}$ penicillin/streptomycin. To test the proliferative effects of normal and preeclamptic AF, BUVEC were seeded at $5000 \mathrm{cells} / \mathrm{cm}^{2}$ and cultured in the presence and absence of $10 \mathrm{ng} / \mathrm{ml}$ VEGF (a gift from Genentech, South San Francisco, CA, USA), alone or together with increasing concentrations of each $\mathrm{AF}$, and with either $0.1 \mu \mathrm{g} / \mathrm{ml}$ of purified anti-human PRL antibodies or control antibodies. The antibodies were purified from rabbit anti-human PRL antiserum or normal rabbit serum on a protein A Sepharose column (Sigma, St Louis, MO, USA) as described. ${ }^{22}$ BUVEC were allowed to proliferate for $48 \mathrm{~h}$ and were pulsed for the last $12 \mathrm{~h}$ with $0.6 \mu \mathrm{Ci}\left[{ }^{3} \mathrm{H}\right]$ thymidine per $15-\mathrm{mm}$ well, as reported. ${ }^{23}$ 


\section{NOS Activity}

BUVEC seeded at approximately $80 \%$ confluence were incubated for $1 \mathrm{~h}$ at $37^{\circ} \mathrm{C}$ in the presence or absence of $10 \mathrm{ng} / \mathrm{ml}$ VEGF, alone or together with increasing concentrations of normal or preeclamptic AF, and with either $0.1 \mu \mathrm{g} / \mathrm{ml}$ of purified anti-human PRL antibodies or control antibodies. NOS activity in cell lysates was measured by conversion of $\left[{ }^{3} \mathrm{H}\right] \mathrm{L}$-arginine into $\left[{ }^{3} \mathrm{H}\right] \mathrm{L}$-citrulline as described previously. ${ }^{15}$

\section{PRL Cleavage by Proteases in AF and Placental Trophoblasts}

The activity of enzymes that cleave PRL to vasoinhibins was assessed in normal and preeclamptic AF by incubating $10 \mu \mathrm{l}$ of each AF sample with $10 \mu \mathrm{l}$ of $\mathrm{pH} 7$ incubation buffer $\left(0.05 \mathrm{M}\right.$ Tris- $\mathrm{HCl}, 0.15 \mathrm{M} \mathrm{NaCl}$, and $\left.0.01 \mathrm{M} \mathrm{CaCl}_{2}\right)$ or of $0.1 \mathrm{M}$ citrate-phosphate buffer $\mathrm{pH} 5.5$, containing $0.15 \mathrm{M}$ $\mathrm{NaCl}$, for $72 \mathrm{~h}$ at $37^{\circ} \mathrm{C}$. Incubation at acid $\mathrm{pH}$ was carried out in the absence or presence of the cathepsin-D inhibitor pepstatin-A (final concentration was $1.4 \mu \mathrm{M}$ ). The reaction was stopped by the addition of reducing Laemmli buffer followed by boiling the samples for $5 \mathrm{~min}$ and fractionating on $15 \%$ SDS-PAGE western blots. Procathepsin-D and cathepsin-D were analyzed in $20 \mu \mathrm{l}$ of AF using 12\% SDS-PAGE western blots probed with $0.8 \mu \mathrm{g} / \mathrm{ml}$ anti-cathepsin-D polyclonal antibody (Santa Cruz Biotechnology Inc., Santa Cruz, CA, USA). Placental trophoblasts were obtained by stripping the amnion from the chorio-decidua, cutting the basal plate, and excising a region from the central area of the placenta. Trophoblasts were stored at $-80^{\circ} \mathrm{C}$ until lysed with a glass homogenizer in cold lysis buffer $(0.5 \%$ Nonidet P- $40,0.1 \%$ SDS, $50 \mathrm{mM}$ Tris, $150 \mathrm{mM} \mathrm{NaCl}, 1 \mu \mathrm{g} / \mathrm{ml}$ aprotinin, and $100 \mu \mathrm{g} / \mathrm{ml}$ phenylmethylsulfonyl fluoride, $\mathrm{pH}$ 7), followed by homogenization by a Polytron PT 10-35 (Kinematica, Switzerland) for $10 \mathrm{~s}$ at a setting of 4 . Cleavage of PRL by trophoblasts was determined by incubating $200 \mathrm{ng}$ of human PRL standard in $5 \mu \mathrm{l}$ of $0.1 \mathrm{M}$ Tris (pH 7.4) mixed with $5 \mu \mathrm{l}$ of different concentrations of trophoblast lysate protein and $10 \mu \mathrm{l}$ of $0.1 \mathrm{M}$ citrate buffer $\mathrm{pH} 4.2$ containing $0.15 \mathrm{M} \mathrm{NaCl}$. Cleaved-PRL products were investigated on reducing $15 \%$ SDS-PAGE western blots.

\section{Statistical Analysis}

Data are presented as mean \pm s.e.m. As appropriate, Student's unpaired $t$-test or one-way ANOVA followed by Tukey's test to compare individual means was used for statistical comparisons. Correlations between variables were analyzed using the Spearman's correlation coefficient. The significance level was set at $5 \%$.

\section{RESULTS}

\section{PRL and Vasoinhibins in Serum, Urine, and AF}

PRL levels in serum, urine, and AF as determined by IRMA, were within the range of values previously reported at the end of gestation. ${ }^{16,24,25}$ PRL concentrations in serum were
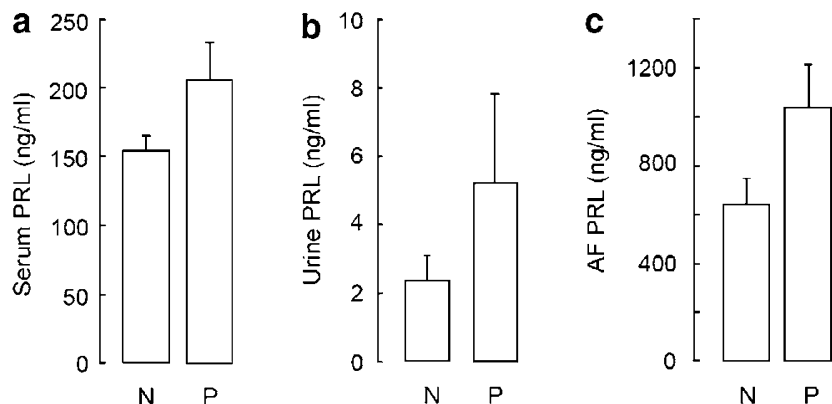

Figure 1 Concentrations of PRL determined by IRMA in the serum (a), urine (b), and AF (c) of women with preeclampsia (P) or with normal pregnancy (N). Bars are means \pm s.e.m. of 8 normal and 13 preeclamptic women.

60-fold higher than in urine, and 4-fold lower than in AF (Figure 1). In preeclamptic women, the mean concentration of PRL in serum, urine, and AF was higher than but not statistically different from levels in normal pregnant women (Figure 1). Because all bioactive vasoinhibins contain the $\mathrm{N}$ terminus of PRL, ${ }^{14}$ the presence of vasoinhibins in serum and urine was investigated by immunoprecipitation with antihuman PRL antiserum followed by western blots using a $\mathrm{mAb}$ that selectively recognizes the $\mathrm{N}$-terminal region of PRL (Figure 2). As expected, the $\mathrm{N}$-terminal $\mathrm{mAb}$ reacted with the standard preparations of full-length $23 \mathrm{kDa}$ PRL, 16, and $14 \mathrm{kDa}$ vasoinhibins. In the serum samples, the light chain of immunoglobulin molecules, which has a mass of approximately $25 \mathrm{kDa}$, created an artifact that interfered with the detection of the full-length $23 \mathrm{kDa}$ PRL. Nevertheless, serum contained immunoreactive proteins of 18,16 , and $14 \mathrm{kDa}$ (Figure 2a) that may correspond to vasoinhibins, which vary in size between 12 and $18 \mathrm{kDa}$ and contain the $\mathrm{N}$-terminal end of PRL. ${ }^{14}$ The vasoinhibin-like immunoreactive proteins were absent in the serum of non-pregnant women (data not shown). The combined densitometric values of the three vasoinhibin-like proteins were significantly higher in preeclamptic serum than in serum from normal pregnant women (Figure 2b). In the urine, detection of $23 \mathrm{kDa}$ PRL was impaired by its low concentration and interference by other proteins at and above $19 \mathrm{kDa}$. However, vasoinhibinlike proteins of 18,16 , and $14 \mathrm{kDa}$ were found in the urine of preeclamptic women but not of normal pregnant (Figure 2c and d) nor of non-pregnant women (data not shown). Owing to the higher levels of PRL, AF proteins were evaluated by western blots using the $\mathrm{N}$-terminal $\mathrm{mAb}$ without the previous immunoprecipitation step. PRL-immunoreactive proteins of $25,23,16,14,12$, and $9 \mathrm{kDa}$ were detected in $\mathrm{AF}$, and the smaller $(<23 \mathrm{kDa})$ PRLs were more abundant in preeclamptic than in normal women (Figure 2e). The combined densitometric values of the 25 and $23 \mathrm{kDa}$ PRLs in preeclamptic AF were similar to levels in normal AF (Figure 2f), whereas the combined densitometric values of the 16, 14, 12 , and $9 \mathrm{kDa}$ vasoinhibin-like proteins were significantly higher in preeclamptic than in normal AF (Figure 2g). 
a

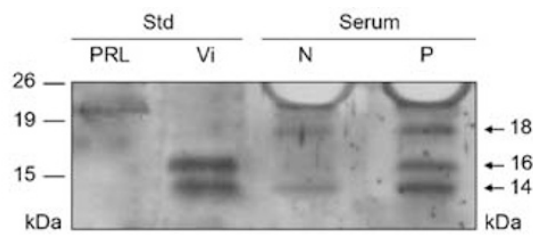

C

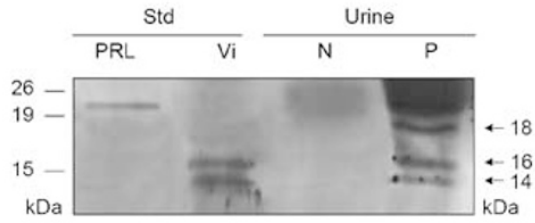

e

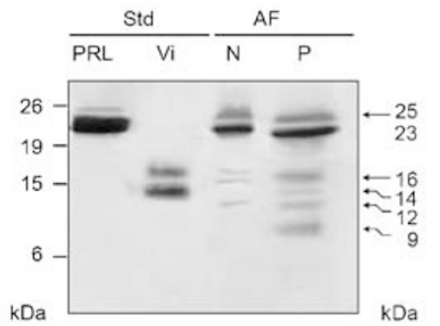

f
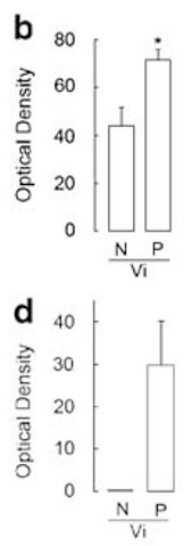

g

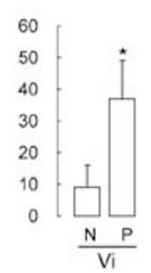

Figure 2 Representative western blots of serum (a), urine (c), and AF samples (e) from women with preeclampsia $(P)$ or with normal pregnancy (N). Before western blot analysis, serum and urine samples were immunoprecipitated with an anti-PRL antiserum, whereas the samples of AF were immunoblotted without the previous immunoprecipitation step. All blots were probed with an anti-PRL mAb that reacts with the N-terminal end of PRL. PRL and vasoinhibin (Vi) standards (Std) are indicated. Combined densitometric values of the 18,16 , and $14 \mathrm{kDa}$ PRL bands were determined in serum (b) and urine (d) samples processed by immunoprecipitation western blots similar to (a and $\mathbf{c}$ ), respectively. Combined densitometric values of the 25 and $23 \mathrm{kDa}$ PRL bands (f), and of the smaller $(16,14,12$, and $9 \mathrm{kDa}) \mathrm{PRL}$ bands $(\mathbf{g})$ in AF were determined in samples processed by western blots similar to (e). Bars are means \pm s.e.m. of samples from the 8 normal and 13 preeclamptic women. ${ }^{\star} P<0.05$ vs values from normal women.

\section{Vasoinhibins in Preeclamptic AF Inhibit VEGF-Induced Proliferation and NOS Activity in Endothelial Cells}

To investigate further the nature of the endogenous peptides, we analyzed whether preeclamptic AF contains factors able to inhibit endothelial cell proliferation and NOS activity, two well-known effects of vasoinhibins. ${ }^{14}$ Treatment with normal or preeclamptic AF did not affect the basal proliferation of BUVEC; however, preeclamptic AF, but not normal AF, inhibited VEGF-induced proliferation of the endothelial cells (Figure 3a). In the absence of VEGF, normal AF stimulated NOS activity although preeclamptic AF was inactive (Figure $3 \mathrm{~b})$. Also, preeclamptic AF, but not normal AF, inhibited VEGF-induced stimulation of NOS activity (Figure 3b). The concentration of VEGF in preeclamptic AF was lower than in normal $\operatorname{AF}(5.7 \pm 1.5$ vs $22.3 \pm 10 \mathrm{pg} / \mathrm{ml} ; P<0.05)$, which might explain the lack of stimulatory effect of preeclamptic AF on basal NOS activity. However, in the presence of exogenous VEGF the inhibitory properties of preeclamptic AF indicate the presence of factors blocking the effects of VEGF.
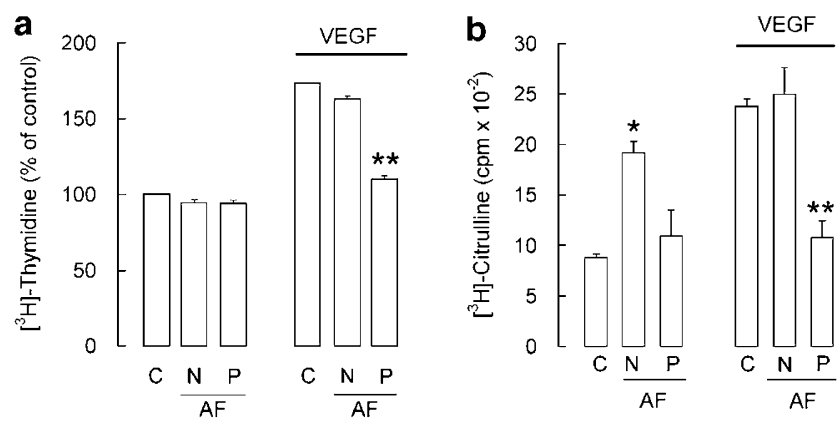

Figure 3 Effect of normal $(\mathrm{N})$ and preeclamptic $(\mathrm{P})$ AF on the proliferation (a) and NOS activity (b) of endothelial cells. Endothelial cells were incubated with $1 \% \mathrm{AF}$ in the absence or presence of $10 \mathrm{ng} / \mathrm{ml} \mathrm{VEGF}$. The control groups (c) were untreated. Values are means \pm s.e.m. of 8 normal and 13 preeclamptic AF samples. ${ }^{\star} P<0.05$ vs control in the absence of VEGF and $A F ;{ }^{*} P<0.05$ vs normal $A F$ in the presence of VEGF.

To investigate whether vasoinhibins are responsible for the inhibitory actions of preeclamptic AF on endothelial cells, we determined the effect of anti-PRL antibodies that can neutralize vasoinhibins. These antibodies blocked the ability of the vasoinhibins standard to inhibit VEGF-induced endothelial cell proliferation and NOS activity (data not shown). Increasing concentrations of normal AF, with or without anti-PRL antibodies or control antibodies, did not modify VEGF-induced proliferation and NOS activity in BUVEC (Figure 4a and c), whereas treatment with increasing concentrations of preeclamptic $\mathrm{AF}$ inhibited both actions of VEGF (Figure $4 \mathrm{~b}$ and $\mathrm{d}$ ). However, the combination of preeclamptic AF and VEGF with anti-PRL antibodies, but not with control antibodies, resulted in mitogenic responses that were comparable to those observed with VEGF alone, indicating that anti-PRL antibodies block the antiangiogenic properties of preeclamptic AF (Figure 4b). Also, anti-PRL antibodies reversed the inhibition of NOS activity by high levels of preeclamptic AF (Figure 4d). Control antibodies had no effect on NOS activity.

\section{Cleavage of PRL by AF and by Placental Trophoblasts}

To determine if AF contains neutral proteases that are able to generate vasoinhibins from PRL, the AF of normal and preeclamptic women was incubated at $\mathrm{pH} 7$ for $72 \mathrm{~h}$ at $37^{\circ} \mathrm{C}$ (Figure 5a). PRL proteolytic products were evaluated in $10 \mu \mathrm{l}$ of AF, because the quantity of naturally occurring vasoinhibins in this volume is too low to be detected by western blots. No additional products were generated from PRL in AF incubated at $\mathrm{pH} 7$, indicating the absence of proteases that can cleave PRL at the physiological $\mathrm{pH}$ of AF, and therefore, that vasoinhibins in the AF are likely to originate from PRL cleaved at an uteroplacental site. However, when AF was incubated at acid $\mathrm{pH}$, immunoreactive bands of 14 and $8 \mathrm{kDa}$ were seen (Figure 5a). In support of cathepsin-D being the responsible protease, the generation of the 14 and the $8 \mathrm{kDa}$ products at acidic $\mathrm{pH}$ was inhibited by the cathepsin-D inhibitor pepstatin-A (Figure 5a). Moreover, the levels of 

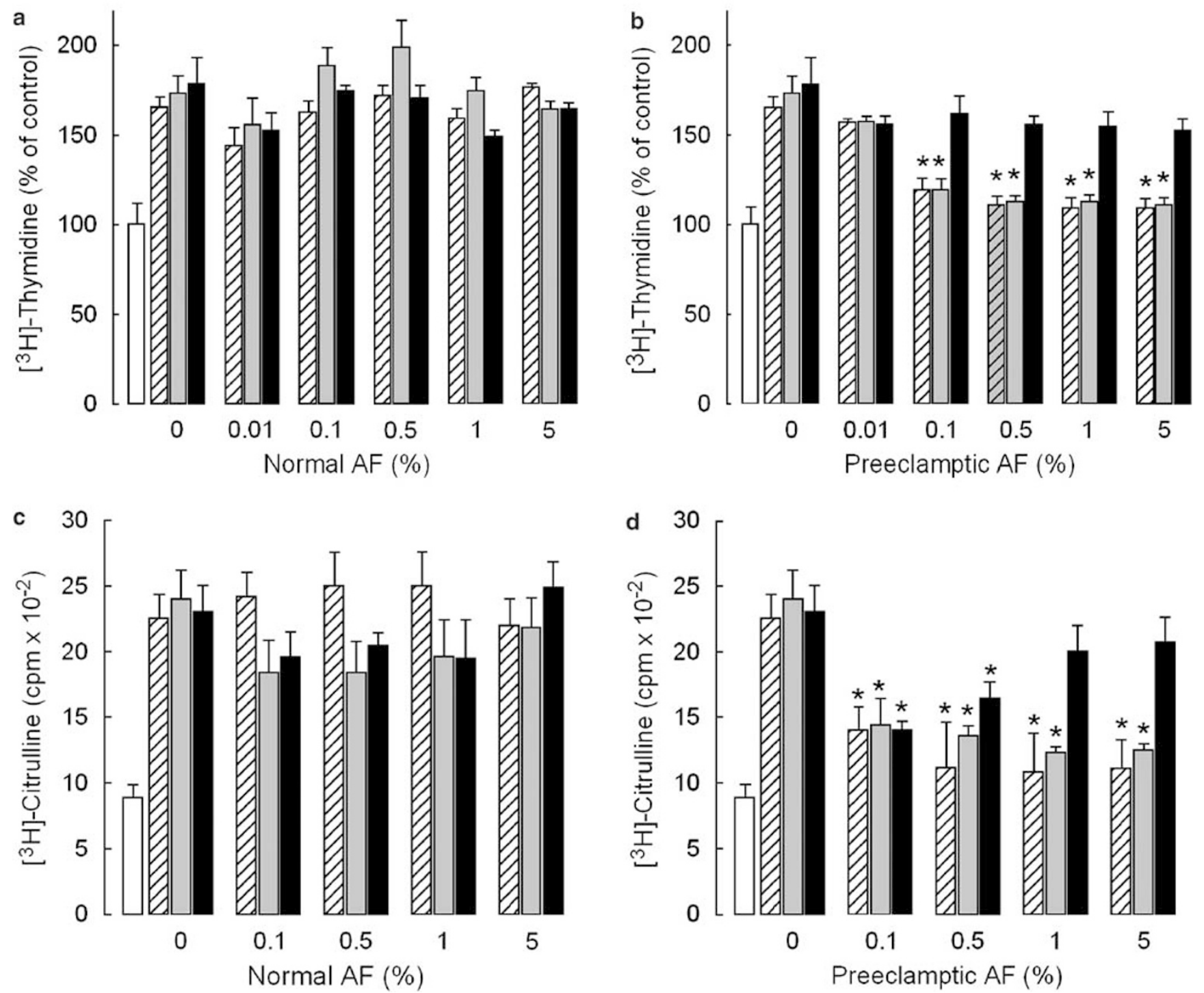

Figure 4 Effect of neutralizing anti-PRL antibodies on the inhibition by normal and preeclamptic AF of endothelial cell proliferation (a and $\mathbf{b})$ and NOS activity (c and d). Endothelial cells were incubated with or without increasing concentrations of AF in the absence or presence of $10 \mathrm{ng} / \mathrm{ml} \mathrm{VEGF,} \mathrm{with}$ either $0.1 \mu \mathrm{g} / \mathrm{ml}$ purified anti-PRL polyclonal antibodies (anti-PRL) or control antibodies (control lgG). Values are means \pm s.e.m. of 8 normal and 13 preeclamptic AF. ${ }^{*} P<0.05$ vs VEGF value in the absence of preeclamptic AF.

procathepsin- $\mathrm{D}$, the $52 \mathrm{kDa}$ precursor of cathepsin-D, and mature cathepsin-D $(33 \mathrm{kDa})$ were similar in western blots of normal and preeclamptic AF (Figure 5b). Incubation at acidic $\mathrm{pH}$ reduced the levels of PRL and its proteolytic products in normal but not in preeclamptic AF. The combined densitometric values of 23,14 , and $8 \mathrm{kDa}$ PRLs were markedly reduced after acid $\mathrm{pH}$ incubation in normal, but not in preeclamptic $\mathrm{AF}(33.2 \pm 10.7$ vs $90 \pm 12 \%$ of corresponding $\mathrm{pH} 7$ value, respectively) (Figure $5 \mathrm{c}$ ). This reduction was abolished by pepstatin-A, implicating cathepsin-D as the responsible protease. In support of the conclusion that vasoinhibins are generated by the placenta, incubation of the PRL standard with lysates from placental trophoblasts at an acidic $\mathrm{pH}$, resulted in its partial conversion to fragments of 14 and $8 \mathrm{kDa}$ (Figure 5d). Cleavage was dose-dependent, and optical density values, relative to that of the control PRL band incubated in the absence of trophoblast, showed a significantly higher generation of PRL fragments by trophoblast lysates from preeclamptic patients than from normal women (Figure 5e). Addition of pepstatin-A to the incubation mixture abolished proteolytic cleavage, indicating that cathepsin-D is the responsible enzyme (Figure $5 \mathrm{~d}$ and e). 


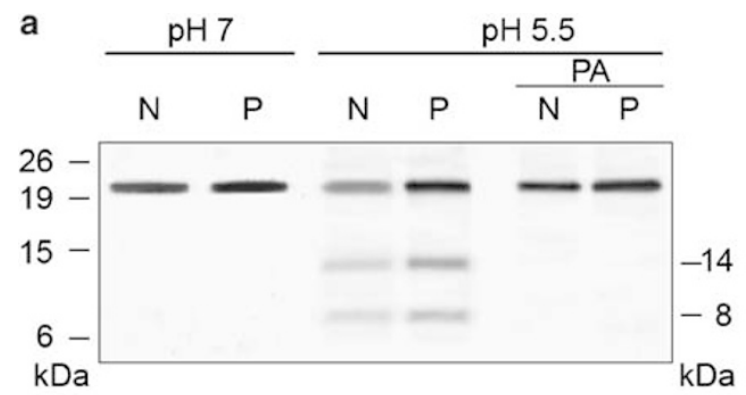

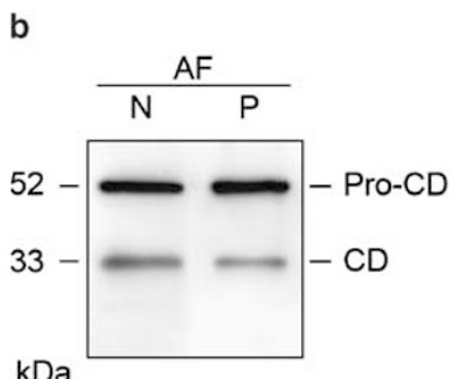

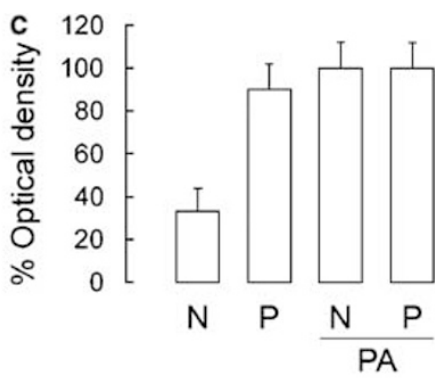

d

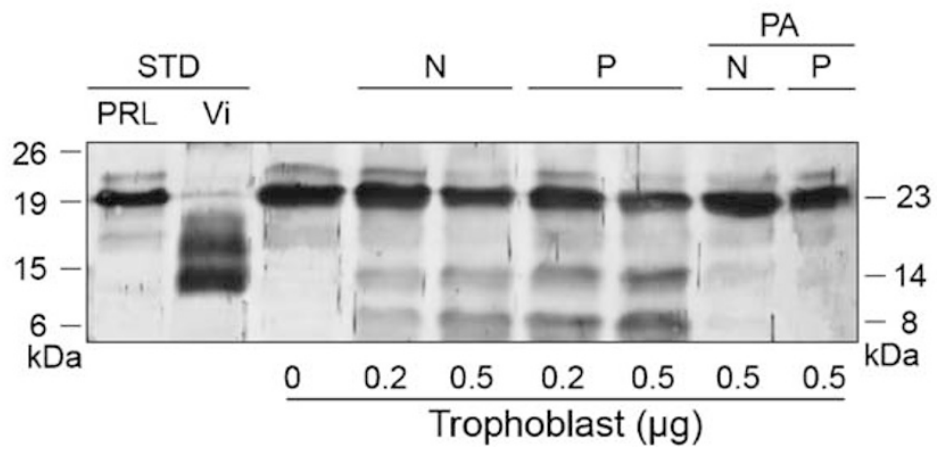

Figure 5 (a) Western blot analysis of the proteolytic products generated from $\mathrm{PRL}$ in normal (N) and preeclamptic (P) AF after incubation at pH 7 or at pH 5.5 for $72 \mathrm{~h}$ at $37^{\circ} \mathrm{C}$ in the absence or presence of pepstatin-A (PA). (b) Western blot detection of procathepsin-D (Pro-CD) and cathepsin-D (CD) in AF from normal and preeclamptic women. (c) Combined densitometric values of all PRL isoforms in normal and preeclamptic $\mathrm{AF}$ incubated $72 \mathrm{~h}$ at pH 5.5 expressed relative to the levels of $23 \mathrm{kDa}$ PRL in the corresponding AFs incubated at $\mathrm{pH}$ 7. (d) Western blot analysis of proteolytic products of PRL obtained

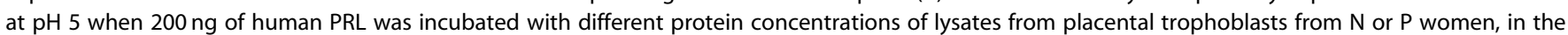
absence or presence of PA. (e) Combined densitometric values of the 14 and $8 \mathrm{kDa}$ vasoinhibins (Vi) expressed relative to the levels of the $23 \mathrm{kDa}$ PRL band from the control PRL standard incubated in the absence of trophoblasts. Values are means \pm s.e.m. of three independent experiments.

\section{Correlations between Birth Weight and Inhibition of Endothelial Cell Proliferation and PRL + Vasoinhibins Concentration in Preeclamptic AF}

Because antiangiogenic factors in AF appear to be produced within the uteroplacental unit, analysis of the correlation between birth weight and vasoinhibin levels in the AF could help elucidate a possible role of vasoinhibins in the abnormal function of the preeclamptic placenta. Since there is no available quantitative assay specific for vasoinhibins, their correlations were established using (a) an IRMA that measures all PRL isoforms (PRL + vasoinhibins) and (b) by evaluating the antiangiogenic properties of the AF, which can be attributed to vasoinhibins, because they were abolished by immunoneutralization of vasoinhibins.

Consistent with the inhibition of VEGF actions by vasoinhibins in preeclamptic $\mathrm{AF}$, there was a direct correlation $(r=0.599, P<0.05)$ between the inhibition of the VEGF-induced proliferation of endothelial cells by preeclamptic $\mathrm{AF}$ and the levels of $\mathrm{PRL}+$ vasoinhibins in $\mathrm{AF}$ (Figure 6a), whereas no significant correlation was observed between these parameters when normal AF was analyzed $(r=-0.323, P<0.387)$. Also, regression analysis indicated that in women with preeclampsia, but not in control women $(r=-0.072, P<0.839)$, there was an inverse correlation $(r=-0.839, P<0.005)$ between birth weight and the inhibition of VEGF-induced proliferation of endothelial cells by preeclamptic AF (Figure 6b). Furthermore, birth weight showed an inverse correlation with $\mathrm{PRL}+$ vasoinhibins concentration $(r=-0.576, P<0.05)$ in preeclamptic $\mathrm{AF}$ (Figure 6c) but not with their concentration in normal AF $(r=-0.394, P<0.327)$. The inhibitory properties of preeclamptic AF upon NOS activity did not correlate with the concentration of PRL + vasoinhibins in the AF samples $(r=0.041, P<0.878)$, or with birth weight $(r=0.256$, $P<0.382)$.

\section{DISCUSSION}

This study investigated the presence of vasoinhibins and their possible contribution to endothelial cell dysfunction and reduced birth weight in preeclampsia. We report that vasoinhibins are elevated in serum, urine, and AF of preeclamptic women and that the concentrations of vasoinhibins in $\mathrm{AF}$ and their antiangiogenic actions correlate with low birth weight in preeclampsia.

The role of PRL in the pathogenesis of preeclampsia was first suggested 30 years ago $^{26}$ and was recently reviewed. ${ }^{27}$ The osmoregulatory ${ }^{28}$ and hypertensive effects of PRL, ${ }^{29,30}$ together with the increased concentration of the hormone in maternal blood throughout pregnancy and its high levels in $\mathrm{AF}^{16}$ led investigators to propose that upregulation of PRL could contribute to hypertension associated with preeclampsia. More recently, the knowledge that defective 

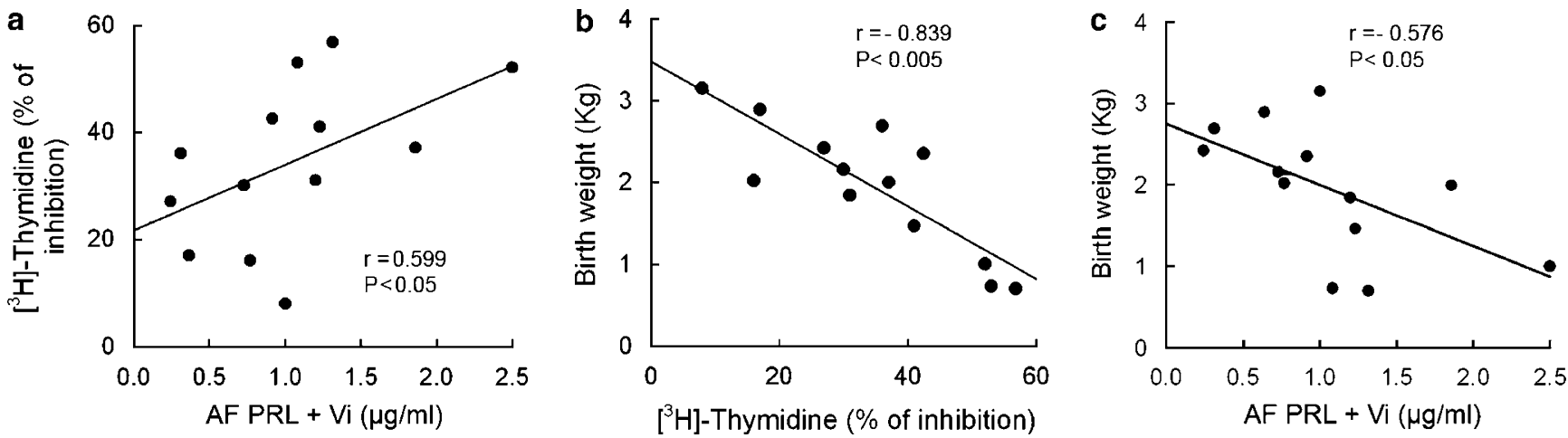

Figure 6 Inhibition of VEGF-induced proliferation of endothelial cells by AF in relation to immunoreactive PRL + vasoinhibins concentration measured by IRMA in each AF sample (a) and birth weight (b) in women with preeclampsia. Birth weight as a function of PRL + vasoinhibins concentration in AF (c) in women with preeclampsia.

placental angiogenesis is a primary event in preeclampsia, ${ }^{2}$ and the discovery that PRL is proteolytically processed to fragments (vasoinhibins) with antiangiogenic and vasoconstrictive properties ${ }^{14}$ strengthened the possibility that PRL is involved in this syndrome. ${ }^{27}$ However, follow-up studies failed to show significant changes associated with preeclampsia in maternal, fetal, or AF levels of PRL as measured by radioimmunoassay ${ }^{16,31}$ and the presence of vasoinhibins in preeclamptic women was not examined.

Here, we confirm previous findings ${ }^{16,31}$ showing that the PRL concentration in serum and AF does not differ significantly between normal and preeclamptic pregnancies when measured by a non-denaturing immunoassay. Also, with this method, we determined for the first time, the levels of PRL in the urine of preeclamptic women, and found them to be similar to those of normal pregnancies. Importantly, using immunoblotting methodology, we found higher levels of PRL-immunoreactive proteins ranging from 9 to $18 \mathrm{kDa}$ in all three biological fluids of preeclamptic women than of normal women. These PRLs may correspond to vasoinhibins, since they have masses similar to those reported for vasoinhibins $(12-18 \mathrm{kDa}),{ }^{14}$ and they react with the N-terminalspecific monoclonal antibody, suggesting that they are Nterminal fragments of the hormone. We found no evidence that vasoinhibins are present in the serum of non-pregnant women, confirming a previous observation that a $16 \mathrm{kDa}$ PRL is present in the circulation of pregnant women but not of non-pregnant women. ${ }^{32}$ It is possible that the higher levels of vasoinhibins result from the cleavage of circulating PRL, which is also high during pregnancy. A 14-kDa PRL has been detected previously in normal $\mathrm{AF}^{33}$ and vasoinhibins have been measured in the serum of patients with postpartum cardiomyopathy, where this vasoinhibin can cause the disease by impairing cardiac capillary network and function. ${ }^{34}$ Since vasoinhibins have reduced immunological reactivity compared to whole, unmodified $23 \mathrm{kDa} \mathrm{PRL},{ }^{35}$ it is possible that their larger proportion in preeclampsia is underestimated by non-denaturing immunoassays. However, their prominence in preeclampsia suggests that they are functionally linked to the disease.

Here, we show that the higher levels of vasoinhibins in preeclamptic AF result in VEGF-blocking activity. Preeclamptic AF inhibited VEGF-induced endothelial cell proliferation and NOS activity, and these actions were reversed by immunoneutralization of vasoinhibins in AF. The effect of the antibodies is consistent with the fact that vasoinhibins, and not unmodified PRL, inhibit VEGF stimulation of endothelial cell proliferation and NOS activity, ${ }^{15}$ and that vasoinhibins, but not unmodified PRL, increase in preeclamptic AF. Recent evidence has shown that endogenous vasoinhibins suppress vasodilation and angiogenesis ${ }^{36}$ and promote vascular regression in ocular tissues, ${ }^{17}$ and mediate microvascular derangements in the heart. ${ }^{34}$ However, the direct effect of vasoinhibins in systemic vascular disease has not been addressed, and the mechanisms of action of vasoinhibins are only partially known. ${ }^{14}$ Vasoinhibins act directly on endothelial cells through a still unidentified saturable highaffinity binding site distinct from the PRL receptor, ${ }^{37}$ and they inhibit VEGF-mediated activation of MAPK at the level of ras $^{38}$ and can block VEGF-induced activation of endothelial NOS by the inhibition of mobilization of intracellular calcium. ${ }^{15}$

Vasoinhibins were investigated in AF to monitor their production by the uteroplacental tissue, with the notion that their VEGF-blocking activity could contribute to defective angiogenesis in preeclampsia. Indeed, we found no evidence for neutral proteases able to cleave PRL in the AF at a physiological $\mathrm{pH}$, suggesting that PRL is not cleaved in the AF but in the uteroplacental tissue instead. However, when the $\mathrm{AF}$ was acidified, PRL was cleaved to 14 and $8 \mathrm{kDa}$ fragments. The responsible protease was cathepsin-D, since this enzyme generates similar fragments from intact human PRL, ${ }^{19,39}$ and the cathepsin-D inhibitor, pepstatin A, prevented the cleavage of PRL by the acidified AF. These findings indicate that endogenous cathepsin-D in AF can generate vasoinhibins from PRL, but the acidic conditions required suggest that such 
cleavage would not occur in the AF, but in the uteroplacental tissue. Previous work indicates that cathepsin-D is expressed in the decidual-placental tissue and acidic conditions can occur locally in association with placental hypoxia in preeclampsia. ${ }^{40}$ Indeed, our work shows that cathepsin-D from placental trophoblasts cleaves PRL to vasoinhibins and that its activity is increased in preeclampsia. In addition, the finding that PRL and vasoinhibins were more resistant to cathepsin-D-mediated degradation in preeclamptic AF than in normal AF would suggest that the elevated levels of vasoinhibins in AF from women with preeclampsia may be due to both their increased generation and reduced proteolytic degradation by placental cathepsin-D. It is unclear how cathepsin-D would efficiently cleave but not degrade PRL in preeclampsia. A possible explanation involves the absence in the preeclamptic setting of peptidases able to degrade PRL that are activated by cathepsin-D. Indeed, cathepsins activate several proteases, including matrix metalloproteases, ${ }^{41}$ which cleave but also degrade PRL. ${ }^{39}$

Consistent with vasoinhibins being able to interfere with placental function, we observed that the birth weight of newborns from mothers with preeclampsia correlated inversely with the concentration of PRL + vasoinhibins in the corresponding AFs and the ability of factors present in AF to inhibit endothelial cell proliferation. These findings support antiangiogenic PRL moieties (vasoinhibins) as pivotal antiangiogenic factors in preeclamptic AF and suggest that they may contribute to the low birth weight associated with preeclampsia. Compromised actions of VEGF leading to reduced angiogenesis underlie abnormal placentation, a cause for fetal growth restriction in preeclampsia. ${ }^{42}$ Likewise, an antiangiogenic environment during the second half of gestation may limit birth weight by reducing adipose tissue accretion in the fetus. Up to $40 \%$ of the variability in birth weight can be explained by the different amounts of adipose tissue of newborns, ${ }^{43}$ and fetal adipose tissue mass is sensitive to angiogenesis inhibitors. ${ }^{44}$

In contrast to inhibition of endothelial cell proliferation, there was no correlation between the weight of newborns in preeclampsia and inhibition of VEGF-induced NOS activity and PRL + vasoinhibins concentration in AF; this observation may imply that inhibition of VEGF-induced NOS activity in preeclampsia involves factors other than vasoinhibins and that it is not an essential part of the mechanism that downregulates angiogenesis and affects fetal growth in preeclampsia. In this regard, we found that in the absence of VEGF, normal AF stimulated NOS activity but did not trigger endothelial cell proliferation. Nevertheless, NO donors increase birth weight ${ }^{45}$ inhibition of NO synthesis by vasoinhibins can lead to vasoconstriction, ${ }^{15}$ a major cause for a decline in uteroplacental perfusion, ${ }^{9,11}$ and reduced NO levels have been reported early in pregnancy in the AF of women with subsequent preeclampsia. ${ }^{8}$ Perhaps, if assayed before the onset of preeclampsia, inhibition of NOS activity by vasoinhibins might correlate with low birth weight. In any case, additional studies verifying the higher generation of vasoinhibins by decidual-placental tissues are needed to help understand their physiological significance for defective placentation and reduced birth weight in preeclampsia.

In conclusion, this work reports for the first time that vasoinhibins are increased in the serum, urine, and AF of preeclamptic women at the end of gestation. We propose that vasoinhibins, acting to reduce the angiogenic and vasodilating actions of VEGF, contribute to endothelial cell dysfunction and reduced birth weight in preeclampsia. Future work is required to investigate the origin of vasoinhibins associated with preeclampsia, to determine whether their concentration increases before the clinical manifestations of the disease, and to demonstrate whether these peptides are important factors for normal and altered pregnancy and birth weight.

\section{ACKNOWLEDGEMENTS}

We thank Gabriel Nava and Fernando López-Barrera for technical assistance and Dorothy $D$ Pless for critically editing the manuscript. This work was supported by the National Council of Science and Technology of Mexico (Grant 44387).

1. Sibai B, Dekker G, Kupferminc M. Pre-eclampsia. Lancet 2005;365: 785-799.

2. Lam C, Lim KH, Karumanchi SA. Circulating angiogenic factors in the pathogenesis and prediction of preeclampsia. Hypertension 2005;46:1077-1085.

3. Fukumura D, Gohongi $T$, Kadambi $A$, et al. Predominant role of endothelial nitric oxide synthase in vascular endothelial growth factorinduced angiogenesis and vascular permeability. Proc Natl Acad Sci USA 2001;98:2604-2609.

4. Walford G, Loscalzo J. Nitric oxide in vascular biology. J Thromb Haemost 2003;1:2112-2118.

5. Polliotti BM, Fry AG, Saller DN, et al. Second-trimester maternal serum placental growth factor and vascular endothelial growth factor for predicting severe, early-onset preeclampsia. Obstet Gynecol 2003;101:1266-1274.

6. Maynard SE, Min JY, Merchan J, et al. Excess placental soluble fms-like tyrosine kinase 1 (sFlt1) may contribute to endothelial dysfunction, hypertension, and proteinuria in preeclampsia. J Clin Invest 2003;111:649-658.

7. Levine RJ, Maynard SE, Qian C, et al. Circulating angiogenic factors and the risk of preeclampsia. N Engl J Med 2004;350:672-683.

8. Tranquilli AL, Bezzeccheri V, Giannubilo SR, et al. Amniotic vascular endothelial growth factor (VEGF) and nitric oxide (NO) in women with subsequent preeclampsia. Eur J Obstet Gynecol Reprod Biol 2004;113:17-20.

9. Lowe DT. Nitric oxide dysfunction in the pathophysiology of preeclampsia. Nitric Oxide 2000;4:441-458.

10. Podjarny E, Losonczy G, Baylis C. Animal models of preeclampsia. Semin Nephrol 2004;24:596-606.

11. Vatish M, Randeva HS, Grammatopoulos DK. Hormonal regulation of placental nitric oxide and pathogenesis of pre-eclampsia. Trends Mol Med 2006;12:223-233.

12. Ben-Jonathan $\mathrm{N}$, Mershon JL, Allen $\mathrm{DL}$, et al. Extrapituitary prolactin: distribution, regulation, functions, and clinical aspects. Endocr Rev 1996;17:639-669.

13. Maaskant RA, Bogic LV, Gilger S, et al. The human prolactin receptor in the fetal membranes, decidua, and placenta. J Clin Endocrinol Metab 1996;81:396-405.

14. Clapp C, Aranda J, Gonzalez C, et al. Vasoinhibins: endogenous regulators of angiogenesis and vascular function. Trends Endocrinol Metab 2006;17:301-307.

15. Gonzalez C, Corbacho AM, Eiserich JP, et al. 16K-prolactin inhibits activation of endothelial nitric oxide synthase, intracellular calcium mobilization, and endothelium-dependent vasorelaxation. Endocrinology 2004;145:5714-5722. 
16. Luciano AA, Varner MW. Decidual, amniotic fluid, maternal and fetal prolactin in normal and abnormal pregnancies. Obstet Gynecol 1984:63:384-388.

17. Duenas Z, Rivera JC, Quiroz-Mercado $H$, et al. Prolactin in eyes of patients with retinopathy of prematurity: implications for vascular regression. Invest Ophthalmol Vis Sci 2004;45:2049-2055.

18. Corbacho AM, Macotela $Y$, Nava G, et al. Human umbilical vein endothelial cells express multiple prolactin isoforms. J Endocrinol 2000;166:53-62.

19. Piwnica D, Touraine P, Struman I, et al. Cathepsin Dprocesses human prolactin into multiple $16 \mathrm{~K}$-like $\mathrm{N}$-terminal fragments: study of their antiangiogenic properties and physiological relevance. Mol Endocrinol 2004;18:2522-2542.

20. Galfione M, Luo W, Kim J, et al. Expression and purification of the angiogenesis inhibitor $16-\mathrm{kDa}$ prolactin fragment from insect cells. Protein Exp Purif 2003;28:252-258.

21. Cajero-Juarez M, Avila B, Ochoa A, et al. Immortalization of bovine umbilical vein endothelial cells: a model for the study of vascular endothelium. Eur J Cell Biol 2002;81:1-8.

22. Duenas $\mathrm{Z}$, Torner $\mathrm{L}$, Corbacho $\mathrm{AM}$, et al. Inhibition of rat corneal angiogenesis by $16-\mathrm{kDa}$ prolactin and by endogenous prolactin-like molecules. Invest Ophthalmol Vis Sci 1999;40:2498-2505.

23. Ferrara N, Clapp C, Weiner R. The $16 \mathrm{~K}$ fragment of prolactin specifically inhibits basal or fibroblast growth factor stimulated growth of capillary endothelial cells. Endocrinology 1991;129:896-900.

24. Tyson JE, Hwang $P$, Guyda $H$, et al. Studies of prolactin secretion in human pregnancy. Am J Obstet Gynecol 1972;113:14-20.

25. Keely EJ, Faiman C. Measurement of human urinary prolactin as a noninvasive study tool. Clin Chem 1994;40:2017-2021.

26. Horrobin DF. The possible role of prolactin in pre-eclampsia. Zentralb Gynakol 1977;99:526-536.

27. Parra A, Ramirez-Peredo J. The possible role of prolactin in preeclampsia: 2001, a hypothesis revisited a quarter of century later. Med Hypotheses 2002;59:378-384.

28. Horrobin DF, Lloyd IJ, Lipton A, et al. Actions of prolactin on human renal function. Lancet 1971;2:352-354.

29. Horrobin DF, Manku MS, Burstyn PG. Effect of intravenous prolactin infusion on arterial blood pressure in rabbits. Cardiovasc Res 1973;7:585-587.

30. Mills DE, Ward RP. Effect of prolactin on blood pressure and cardiovascular responsiveness in the rat. Proc Soc Exp Biol Med 1986;181:3-8.
31. Ranta T, Stenman UH, Unnerus HA, et al. Maternal plasma prolactin levels in preeclampsia. Obstet Gynecol 1980;55:428-430.

32. Sinha YN, Gilligan TA, Lee DW, et al. Cleaved prolactin: evidence for its occurrence in human pituitary gland and plasma. J Clin Endocrinol Metab 1985;60:239-243.

33. Fukuoka $H$, Hamamoto $R$, Higurashi $M$. Heterogeneity of serum and amniotic fluid prolactin in humans. Horm Res 1991;35(Suppl 1): 58-63.

34. Hilfiker-Kleiner D, Kaminski K, Podewski E, et al. A cathepsin D-cleaved $16 \mathrm{kDa}$ form of prolactin mediates postpartum cardiomyopathy. Cell 2007;128:589-600.

35. Clapp C, Sears PS, Russell DH, et al. Biological and immunological characterization of cleaved and $16 \mathrm{~K}$ forms of rat prolactin. Endocrinology 1988;122:2892-2898.

36. Aranda J, Rivera JC, Jeziorski MC, et al. Prolactins are natural inhibitors of angiogenesis in the retina. Invest Ophthalmol Vis Sci 2005;46: 2947-2953.

37. Clapp C, Weiner Rl. A specific, high affinity, saturable binding site for the 16-kilodalton fragment of prolactin on capillary endothelial cells. Endocrinology 1992;130:1380-1386.

38. D'Angelo $G$, Martini JF, liri $T$, et al. $16 \mathrm{~K}$ human prolactin inhibits vascular endothelial growth factor-induced activation of Ras in capillary endothelial cells. Mol Endocrinol 1999;13:692-704.

39. Macotela $Y$, Aguilar MB, Guzman-Morales J, et al. Matrix metalloproteases from chondrocytes generate an antiangiogenic $16 \mathrm{kDa}$ prolactin. J Cell Sci 2006;119:1790-1800.

40. Moses EK, Freed KA, Higgins JR, et al. Alternative forms of a novel aspartyl protease gene are differentially expressed in human gestational tissues. Mol Hum Reprod 1999;5:983-989.

41. Murphy $G$, Willenbrock $F$, Crabe $T$, et al. Regulation of matrix metalloproteinase activity. Ann NY Acad Sci 1994;732:31-41.

42. Regnault TR, Galan HL, Parker TA, et al. Placental development in normal and compromised pregnancies-a review. Placenta 2002;23(Suppl A):S119-S129.

43. Catalano PM, Drago NM, Amini SB. Factors affecting fetal growth and body composition. Am J Obstet Gynecol 1995;172:1459-1463.

44. Rupnick MA, Panigrahy $D$, Zhang CY, et al. Adipose tissue mass can be regulated through the vasculature. Proc Natl Acad Sci USA 2002;99:10730-10735.

45. Sieroszewski P, Suzin J, Karowicz-Bilinska A. Ultrasound evaluation of intrauterine growth restriction therapy by a nitric oxide donor (L-arginine). J Matern Fetal Neonatal Med 2004;15:363-366. 